\title{
The Fracture Evaluation of NiTi SMA Endodontics Files
}

\author{
Tibério César Uchôa Matheus ${ }^{\mathrm{a}, \mathrm{b} *, \text { Hélio Pereira Lopes }}$, Diana Santana de Albuquerque, \\ Carlos Nelson Elias ${ }^{\mathrm{b}}$, Antônio Márcio Resende do Carmo ${ }^{\mathrm{f}}$, Jorge Otubo ${ }^{\mathrm{a}}$, Carlos Sérgio da Costa Viana ${ }^{\mathrm{b}, \mathrm{c}}$ \\ anstituto Tecnológico de Aeronáutica - ITA, Divisão de Engenharia Mecânica Aeronáutica, \\ 12228-900 São José dos Campos - SP, Brazil \\ ' Instituto Militar de Engenharia, Seção de Engenharia, Mecânica e de Materiais, RJ, Brazil \\ 'Universidade Federal Fluminense, Departamento de Engenharia Metalúrgica, RJ, Brazil \\ ${ }^{\mathrm{d}}$ Universidade Estácio de Sá, Departamento de Odontologia Restauradora, RJ, Brazil \\ 'Universidade de Pernambuco, Departamento de Odontologia Restauradora, PE, Brazil \\ ${ }^{\mathrm{f}}$ Universidade Federal de Juiz de Fora, Departamento de Odontologia Restauradora, MG, Brazil
}

Received: March 19, 2007; Revised: September 25, 2007

\begin{abstract}
The purpose of this study was to evaluate the fracture resistance and the fracture surface of NiTi SMA engine-driven endodontics files submitted to clockwise torsion. The maximum angular deflection and the maximum torque were analyzed without axial loading. The helical plastic deformations and the fracture surface morphology were evaluated by Scanning Electron Microscopic. The results showed that there was a significant statistical difference in the maximum fracture torque and no statistical difference for the angular deflection for the analyzed files. In relation to the maximum torque at the instant of the fracture, one of the brand presented better performance than the other. According to Scanning Electron Microscopic evaluation, all the files showed ductile fracture morphology.
\end{abstract}

Keywords: endodontics files, NiTi, SMA, torsion fracture

\section{Introduction}

Nickel-titanium (NiTi) endodontic instruments have been introduced to facilitate the instrumentation of curved canals. NiTi Shape Memory Alloys (SMA) instruments have the combination of good biocompatibility, good mechanical strength, and specific properties, such as the shape memory effect (SME) and superelasticity (SE). NiTi instrument can bend far more than stainless-steel instruments before exceeding their yield point ${ }^{1}$. This flexibility is an important property that allows the preparation of curved canals while minimizing deviation ${ }^{2}$. Despite of this increased flexibility, fracture is still a concern to NiTi instruments, and they have been reported to undergo unexpected fail ${ }^{3}$.

The behavior of NiTi alloys is associated with the stress-induced transformation of the $\beta$ parent phase, austenite, with the B2 cubic crystal structure, to martensite, with a monoclinic B19' structure. Appropriate chemical composition and thermomechanical treatments are required in order to stress-induces the martensitic transformation in NiTi alloys ${ }^{4}$.

The NiTi alloys, with an approximately equiatomic composition, have in addition to high resistance and excellent biocompatibility some special features: the SME and SE. The SME occurs in specific conditions in which the metal is deformed at a certain temperature, the shape recovery temperature is higher than the temperature of deformation. To recover the original shape it is necessary to heat the material above the shape recovery temperature, $\mathrm{A}_{\mathrm{F}}$. At $\mathrm{SE}$ state as far as the shape recovery temperature is lower than the deformation temperature, the shape is recovered when the load is released without heating.

Because of its shape memory properties, Nitinol has been used for such applicatons as pipe couplings and actuators. Its superelastic properties, on the other hand, are used in eyeglass frames, mobile phone antennas, dental braces, endodontics files and endovascuar stents ${ }^{5}$.

The fatigue life of a rotary endodontic instrument could be related to the degree to which it is flexed when placed in a curved root canal, with greater flexures leading to a shorter expected life $\mathrm{e}^{6,7}$. Torsional fracture occurs when the tip or some part of the endodontic file is hindered in a canal while the instrument shaft continues to rotate. In this case, the elastic limit of the metal is exceeded leading to plastic deformation followed by fracture ${ }^{8,9}$. Many factors can affect the torsional strength of endodontic files, such as taper, instrument design, alloy composition and stiffness, manufacturing, flexibility, and rotation direction ${ }^{10}$.

The objective of this study was to compare the performance of the NiTi SMA engine-driven endodontic instruments, when submitted to clockwise torsion test. The evaluated properties were: the angular deflection up to fracture and the maximum torque at the fracture. Also it was evaluated the fracture surface and the shape of spiral of the cutting edge near the immobilizing point of the endodontic instrument after the mechanical testing.

\section{Experimental Procedure}

The analysed nickel-titanium rotary files were $\mathrm{K}^{3}$ Endo (Sybron Endo - USA) and Profile (Dentsply-Maillefer - Switzerland) (\#15 and \#35, lenght of $25 \mathrm{~mm}$ ) with cross section profiles of triple helix and triple $\mathrm{U}$, respectively. Ten files of each size were submitted to the clockwise $(\mathrm{CW})$ rotation. Therefore, 20 files from each manufacturer were tested.

A torsion without axial load was applied to the files with a device attached to Universal Mechanical Testing Machine Emic DL 10000 
(Emic Equipments and Systems for Tests Ltd, São Paulo). This apparatus was similar to the one used by others $\operatorname{studies}^{11,12}$ (Figure 1,2).

The load and the displacement of the thread up to the fracture of the instruments were registered continuously by a microcomputer attached to the testing machine. A chart of the load vs. displacement was obtained.

The determination of the angular deflection and the obtained displacement were converted through the formula:

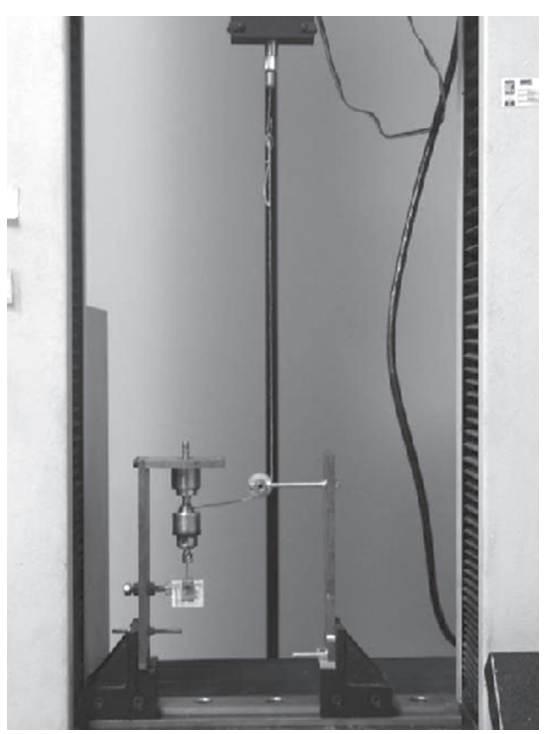

Figure 1. Device attached to Universal Mechanical Testing Machine.

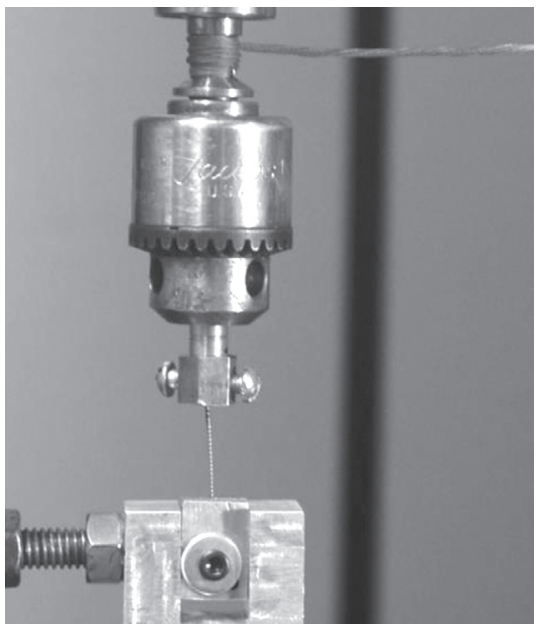

Figure 2. Image close to the instrument during the testing.

$$
\text { Angular Deflection }\left({ }^{\circ}\right)=\frac{\text { displacement }(\mathrm{mm})}{2 \pi \mathrm{R}(\mathrm{mm})} \times 360^{\circ}
$$

The maximum torque at the fracture was calculated through the formula:

Maximum Torque $($ N.m $)=$ Maximum $\operatorname{Load}(\mathrm{N}) \times \mathrm{R}(\mathrm{m})$

After fracture occurrence, the SEM analysis (JEOL, model ISM 5800 IV) was carried out to evaluate any possible alterations of the spirals of the cutting edge together with the point of immobilization and the surface characteristics of the fracture.

In order to observe the spiral of the cutting edge near the fracture surface, as well as the morphological characteristics of the fracture surface, micrographies were taken with varying magnification. To analyze the shape of the spiral, photomicrographies with a lower magnification (60 to 200x) was used and to analyse the morphology of the fracture surface, the photomicrographies were taken with 2000x magnification.

\section{Results and Discussion}

In this study, the evaluation of the angular deflection and the maximum torque were developed in agreement with the ANSI/ADA Specification number $28,1989^{13}$. The test for the evaluation of the torque shows to the dentist the maximum load that could be applied to the instrument.

The obtained charts were used to calculate the angular deflection and the maximum torque up to the fracture. The parametric Student's t-test was applied to the obtained data with $95 \%$ of confidence interval. The results are shown in Table 1.

The maximum angular deflection of the $\mathrm{K}^{3}$ Endo and ProFile instruments, revealed that there was no significant difference between the averages of the tested groups. The same results were observed between the instruments $\mathrm{K}^{3}$ Endo \#35 (Group I B) and ProFile \#35 (Group II B) in relation to the maximum angular deflection. Even though, to some studies ${ }^{11,14}$, the maximum angular deflection in the fracture, for hand instruments of NiTi, has decreased with the increase of the nominal diameter of the endodontic instrument. Other author observed that the angular deflection is not influenced by the increase of the nominal diameter of the instrument ${ }^{15}$. This feature may be explained by the fact that all the efforts to standardize the dimensions of the endodontic instruments, could present discrepancy in dimensions of the instruments even with the same number. Besides, they could have deficient surface finishing presenting irregularities and scratches occurred during the manufacturing process and they act as stress concentrator interfering directly in the obtained results of such endodontic instruments when submitted to mechanical tests ${ }^{16}$.

In the evaluation of the mechanical resistance of the instruments in the torsion test, some different parameters may be used. For some authors ${ }^{11,17}$, the main parameter is the maximum angular deflection that acts as a safety factor in relation to the fracture of the instrument. Larger the angular deflection of an endodontic instrument, the larger will be its toughness and plastic deformation before starting the fracture. This feature of the material is a safety factor because as

Table 1. Average and standard deviation values of the angular deflection and maximum torque.

\begin{tabular}{|c|c|c|c|c|}
\hline & \multicolumn{2}{|c|}{ Angular deflection } & \multicolumn{2}{|c|}{ Maximum torque } \\
\hline & Average $\left({ }^{\circ}\right)$ & Standard deviation & Average $10^{-3}$ N.m & Standard deviation \\
\hline Group I A K ${ }^{3}$ Endo \#15 & 676.40 & 101.60 & 4.95 & 5.73 \\
\hline Group II A ProFile \#15 & 637.20 & 155.70 & 2.99 & 5.58 \\
\hline Group I B K ${ }^{3}$ Endo \#35 & 818.00 & 69.94 & 18.48 & 9.58 \\
\hline Group II B ProFile \#35 & 886.90 & 121.40 & 14.03 & 7.50 \\
\hline
\end{tabular}


far as it goes beyond the limit of resistance to the fracture by torsion of the material ${ }^{18}$.

As to the maximum fracture torque, it was possible to verify statistical differences for the two brands tested with different diameter, increasing with the increase of the nominal diameter of the endodontic instrument. Similar results were obtained in other studies ${ }^{11,17,18}$. Concerning to brand, $\mathrm{K}^{3}$ Endo \#15 (Group I A) it supported higher torque up to fracture when compared to ProFile \#15 brand (Group II A). The same results was presented when it was compared the instruments $\mathrm{K}^{3}$ Endo \#35 (Group I B) and ProFile \#35 (Group II B).

The source of those differences is related to the variation in transversal cross section, and consequently, with the need of a higher load to fracture the instruments of a larger size. It was verified that the $\mathrm{K}^{3}$ Endo instruments supported a higher maximum torque at the instant of the fracture than the ProFile instruments. This may explain the better performance of triple helix $\mathrm{K}^{3}$ Endo file, which has a larger nucleus when submitted to a torsion effort that promotes the stress distribution progressively between the angle of the cutting edge and the canal file (Figure 3). To a transversal cross section of a triple $U$ instrument (ProFile) (Figure 4), which has a smaller nucleus, the stress is concentrated in the canal file much closer to the center line of the instrument than in triple helix ${ }^{19}$. This explain the bettter performance of triple helix $\mathrm{K}^{3}$ Endo in relation to triple U Profile.

Qualitative evaluation by SEM showed a plastic deformation of the spirals of the instrument reversing the original direction near the fracture $( \pm 3 \mathrm{~mm})$ region, as seen in Figure 5, confirming the earlier works ${ }^{11,21}$. In the same figure one can see the presence of grooves patterns at the cutting edge which comes from machining stage that can act as stress raisers during loading. The fracture surface presented microvoids and dimples characteristic of tipical ductile fracture as can be seeing in Figure 6. According to Sawaguchi et al. ${ }^{22}$, fatigue cracks always start at surface irregularities such as scratches as seeing in Figure 5 of this work. It could also start around the inclusions such as TiC and titanium oxide which come from alloy fabrication stage $e^{23,24}$. The fracture surface also showed shear deformation area around the ductile central fibrous region (Figure 5). Similarly, Bahia and Buono ${ }^{25}$, 2005, observed the presence of a small smooth area near the file edge, associated with nucleation and slow crack propagation.

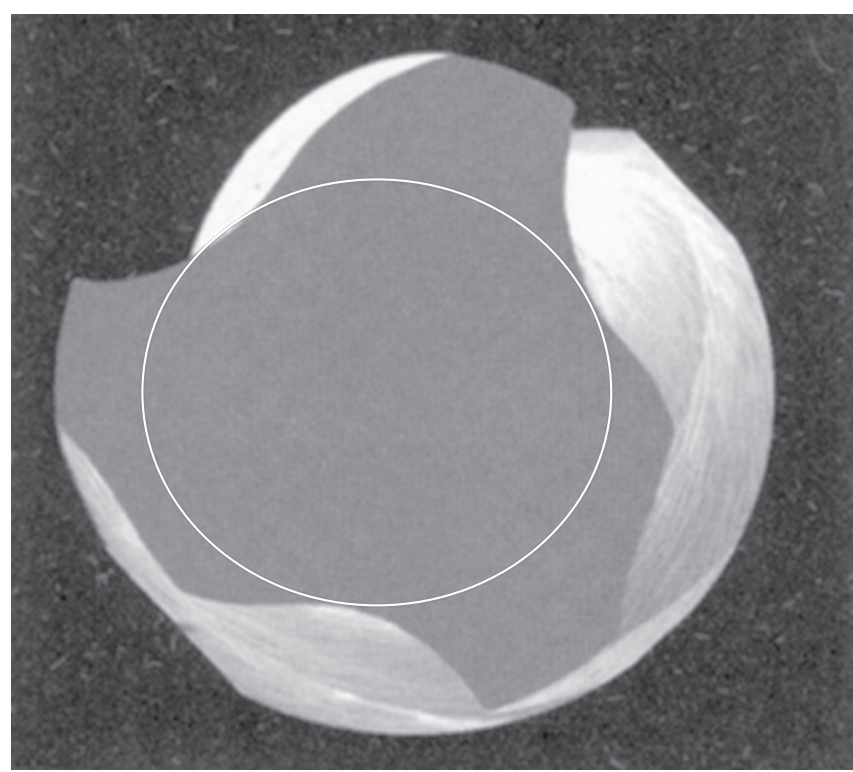

Figure 3. Representation of the $\mathrm{K}^{3}$ Endo instrument with triple helix cross section (Lopes et al..$^{20}$ ).

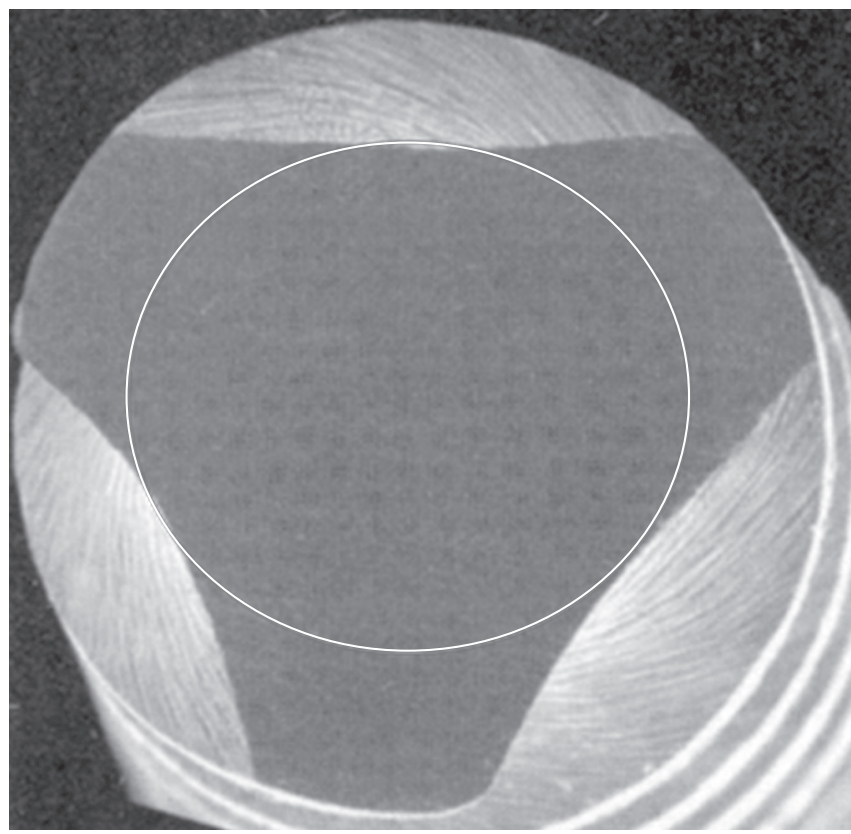

Figure 4. Representation of the ProFile instrument with triple U cross section (Lopes et al. ${ }^{20}$ ).

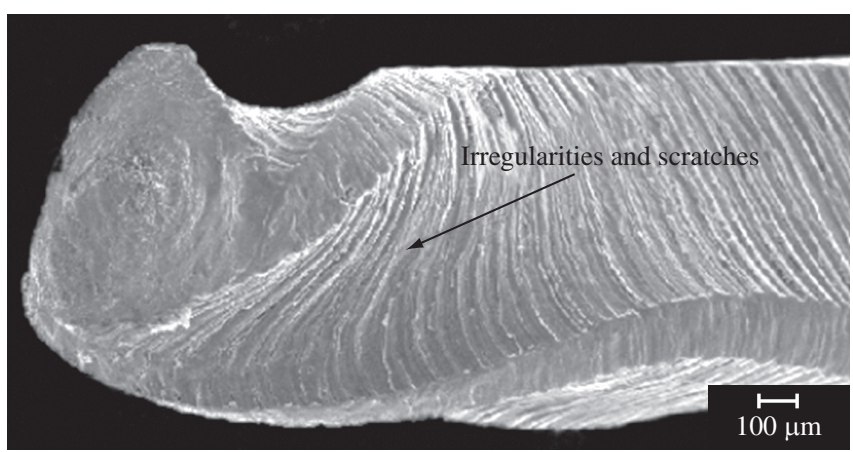

Figure 5. Representative morphology of an endodontic file (ProFile \#15) after mechanical testing, showing the reversion in the direction of the helix. (SEM original magnification - 200x).

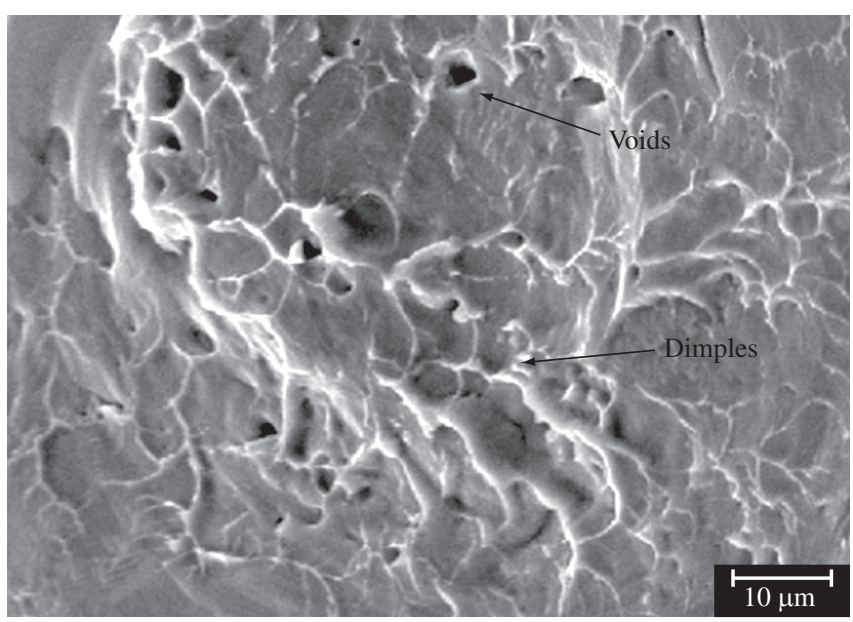

Figure 6. Representative surface fracture morphology of an endodontic file surface $\left(\mathrm{K}^{3}\right.$ Endo \#15), showing the presence of microvoids with varied shapes (SEM original magnification - 2000x). 
The frequency of fracture of the NiTi SMA engine-driven endodontic instruments during the preparation of the root canal may be reduced, according to the manufacturing of the instrument with a better control of material quality, more demanding evaluation of the dimensions and a better surface finishing.

\section{Conclusions}

According to the results, it is conclude that:

- In relation to the maximum angular deflection, there was a variation when comparing the brands ( $\mathrm{K}^{3}$ Endo and ProFile) for the same diameters instruments;

- For maximum torque there was a significant difference between the averages of the tested groups with better perfomance of $\mathrm{K}^{3}$ Endo brand compared to ProFile brand;

- At lower magnification (60 to 200x), all the fractured instrument presented smooth fracture surfaces and perpendicular to their axis. There was a reversion in the direction of the spirals in relation to its original direction when the files were submitted to clockwise torsion. At the cutting edge there were observed grooves patterns from machining that can act as stress raisers during loading; and

- At higher magnification (2.000x), it was observed that the fracture surface presented typical ductile fracture presenting dimples and microvoids.

\section{Acknowledgments}

We would like to acknowledge FAPERJ (grant \#E-26/100.130/06DSC 10) for scholarship to one of the authors and to FAPESP (grant \#00/09730-1), FINEP (grant \#01.04.0255.00 - CT INFRA 03/2003; PROINFRA 01/05, Protocol 153) for financial support.

Thanks to Dentsply for suppling the samples.

\section{References}

1. Walia H, Brantley WA, Gerstein, H. An initial investigation of the bending and torsional properties of Nitinol root canal files. Journal of Endodontics. 1988; 14(7):346-51.

2. Glosson CR. et al. A comparison of root canal preparations using NiTi hand, NiTi engine driven, and K Flex endodontic instruments. Journal of Endodontics. 1995; 21(3):146-51.

3. Cohen S, Burns RC. Pathways of the pulp. $6^{\text {th }}$ ed. St. Louis: Mosby-Year Book, Inc.; 1994. p. 206.

4. Bahia MGA, Martins RC, Gonzalez BM, Buono VTL. Physical and mechanical characterization and the influence of cyclic loading on the behaviour of nickel-titanium wires employed in the manufacture of rotary endodontic instruments. International Endodontics Journal. 2005; 38(11):795-801.

5. Mckelvey AL, Ritchie RO. Fatigue-Crack growth behavior in the superelastic and shape-memory alloy nitinol. Metallurgical and Materials Transactions A. 2001; 32A:731-43.

6. Pruet J, Clement D, Carnes DJ. Cyclic fatigue testing of nickel-titanium endodontic instruments. Journal of Endodontics. 1997; 27(2):77-85.

7. Melo MCC, Bahia MGA, Buono VTL. Fatigue resistance of engine-driven rotary nickel-titanium endodontic instruments. Journal of Endodontics. 2002; 28(11):765-9.
8. Gambarine, G. Torsional and cyclic fatigue testing of ProFile NiTi rotary instruments. Journal of Evolutionary Dentistry. 1999; 2(1):4-14.

9. Blum JY, Machtou P, Micallef JP. Location of contact areas on rotary ProFile instruments in relationship to the forces developed during mechanical preparation on extracted teeth. International Endodontics Journal. 1999; 32(2):108-114

10. Hilt BR, Cunninghan CJ, Shen C, Richards N. Torsional properties of stainless-steel and nickel-titanium files after multiple auto clave sterilizations. Journal of Endodontics. 2000; 26(2):76-80.

11. Seto BG, Nicholls JI, Harrington GW. Torsional properties of twisted and machined endodontic files. Journal of Endodontics. 1990; 16(8):355-60.

12. Lautenschlager EP. et al. Brittle and ductil torsional failures of endodontic instruments. Journal of Endodontics. 1977; 3(5):175-8.

13. American National Standards Institute. American Dental Association. (Council on Dental Materials, Instruments, and Equipment). Specification \# 28 for root canal files and reamers, type K, and \# 58 for root canal files, type H (Hedströen). Journal American Dental Association. 1989; 118(2):239-40.

14. Canalda-Sahli C, Brau-Aguadé E, Berastegui-Jimeno E. A comparison of bending and torsional properties of K-files manufactured with different metallic alloys. International Endodontics Journal. 1996; 29(3):185-9.

15. Carmo AMR. et al. Torsional fracture nickel-titanium engine-driven rotatory instruments. Revista Brasileira de Odontologia. 2002; 59(3):197-99.

16. Lopes HP, Elias CN. Fracture of engine-driven NiTi endodontic instruments. Theoretic and practical concepts. Revista Brasileira de Odontologia. 2001; 58(3):207-10.

17. Rowan MB, Nicholls JI, Steiner J. Torsional properties of stainless steel and nickel-titanium endodontic files. Journal of Endodontics. 1996; 22(7):341-45.

18. Lopes HP. et al. Torsional fracture of stainless-steel and nickel-titanium endodontics files. Revista Paulista de Odontologia. 2001; 23(2):8-12.

19. Turpin YL. et al. Impact of torsional and bending inertia on root canal instruments. Journal of Endodontics. 2001; 27(5):333-36.

20. Lopes HP, Elias CN, Siqueira JF. Instrumentos endodônticos. In: Lopes, HP, Siqueira JF. Endodontia: Biologia e Técnica. $2^{\mathrm{a}}$ ed., Guanabara Koogan, Rio de Janeiro; 2004.

21. Sattapan B. et al. Defects in rotary nickel-titanium files after clinical use. Journal of Endodontics. 2000; 26(3):161-5.

22. Sawaguchi T, Kausträter G, Alejandro Y, Wagner, M.; Eggeler, G. Crack initiation and propagation shape-memory wires in bendingrotation fatigue. Mettalurgical and Materials Transactions A. 2003; 34A:2847-60.

23. Otubo J, Rigo OD, Moura Neto C, Kaufman MJ, Mei PR. Scale up of NiTi shape memory alloy production by EBM. Journal of Physique IV. 2003; 112:873-76.

24. Otubo J, Rigo OD, Moura Neto C, Mei PR. The effects of Vaccum induction melting and electron beam melting techniques on the purity of NiTi shape memory alloys. Materials Science and Engineering A. 2006; 438-40:679-82.

25. Bahia MGA, Buono VTL. Decrease in the fatigue resistance of nickeltitanium rotary instruments after clinical use in curved root canals. Oral Surgery Oral Medicine Oral Pathology Oral Radiology and Endodontics. 2005; 100(2):249-255. 